\title{
PENGARUH DIAMETER TIANG TERHADAP TAHANAN GESEK TIANG DALAM TANAH LEMPUNG
}

\author{
Andikanoza Pradiptiya', A'isyah Salimah ${ }^{2}$ \\ 1,2 Jurusan Teknik Sipil Politeknik Negeri Jakarta \\ andikanoza.pradiptya@sipil.pnj.ac.id, aish.asdm@gmail.com
}

\begin{abstract}
Some buildings impose limits on the foundation displacement that occur with relatively small values so as not to cause structural damage. The test method used was to make a model test box as a testing medium by simulating the actual model into the form of a scale model. The study was conducted using a single pile foundation with reduced scale, made of concrete with a diameter of $0.02 \mathrm{~m}, 0.03 \mathrm{~m}, 0.04 \mathrm{~m}$ and the length of each pile was $0.4 \mathrm{~m}$. The pile model was mounted by pressing into the clay that had been compacted in the test box and then given a tensile load which refers to ASTM D3689-07 procedure E (Constant Rate of Uplift Test). Mobilization of pile friction resistance at critical displacement determined the frictional resistance of the ultimate pile units. The test results showed that the greater the diameter of the pile, the frictional resistance of the ultimate pile units would increase. The increase in frictional resistance of the ultimate pile units showed an average value of around $17.1 \%$.
\end{abstract}

Keywords : Pile foundation, Pile diameter, Friction resistance.

\begin{abstract}
ABSTRAK
Meningkatnya pembangunan hunian mengakibatkan naiknya permintaan akan batako, hal ini tentunya Beberapa konstruksi bangunan memberikan batasan kepada perpindahan tiang yang terjadi dengan nilai yang relatif kecil supaya tidak menyebabkan kerusakan struktur. Metode uji yang dipakai adalah membuat box uji model sebagai media pengujian, dengan mensimulasikan model yang sebenarnya ke dalam bentuk model skala. Penelitian dilakukan menggunakan model pondasi tiang tunggal penampang lingkaran lingkaran skala tereduksi yang terbuat dari beton dengan diameter 0,02 m, 0,03 $m, 0,04 \mathrm{~m}$ dan panjang masing-masing tiang adalah 0,4 $\mathrm{m}$. Model tiang dipasang dengan cara ditekan pada tanah lempung yang sudah dipadatkan dalam box uji kemudian diberikan beban tarik yang mengacu pada ASTM D3689-07 prosedur E (Constant Rate of Uplift Test). Mobilisasi tahanan gesek tiang pada perpindahan tiang kritis menetukan tahanan gesek satuan ultimit. Hasil uji memperlihatkan bahwa semakin besar diameter tiang, tahanan gesek satuan ultimit tiang akan bertambah. Peningkatan tahanan gesek satuan ultimit tiang menunjukkan rata-rata sekitar 17,1\%.
\end{abstract}

Kata kunci : Pondasi Tiang, Diameter Tiang, Tahanan Gesek Tiang.

\section{PENDAHULUAN}

Setiap tanah merupakan material yang unik dan memiliki karakteristik yang kompleks. Semua struktur bangunan bertumpu pada kekuatan tanah yang mendukungnya sehingga di dalam perencanaan struktur bangunan haruslah benar-benar memahami tentang jenis dan karakteristik tanah secara detail. Beberapa konstruksi bangunan memberikan batasan kepada perpindahan pondasi tiang yang terjadi dengan nilai yang relatif kecil supaya tidak menyebabkan kerusakan struktur. Hingga saat ini masih banyak fenomena kerusakan/kegagalan struktur bangunan yang masih sulit diprediksi, antara lain kegagalan pondasi, bangunan miring, tanah longsor maupun jalan amblas. Hal ini diakibatkan oleh kurangnya data dan pemahaman terhadap jenis maupun karakter dari suatu tanah yang mendukung bangunan tersebut. Untuk mendapatkan data dari suatu tanah seperti sifat fisik maupun mekanik dapat 
dilalakukan di laboratorium, sedangkan untuk mengetahui perilaku struktur yang sebenarnya terhadap pembebanan maka haruslah dilakukan uji coba di lapangan. Pengujuian secara langsung di lapangan memerlukan biaya yang sangat tinggi. Untuk mengatasi kondisi ini maka media lapangan dipindahkan ke laboratorium dengan menggunakan model skala tertentu. Untuk merealisasikan gagasan ini maka dapat dilakukan dengan pembuatan 'box uji model' dengan ukuran skala model tertentu yang dapat menampung berbagai macam model struktur yang diamati. Dari hasil pengujian dengan skala model ini diharapkan dapat memperoleh data respon struktur yang lebih dekat dengan kondisi di lapangan yang sebenarnya, serta biaya yang lebih murah.

\section{Tahanan gesek termobilisasi pondasi tiang pada tanah lempung.}

Reese dkk. [1] memberikan kurva normalisasi hubungan tahanan gesek dan penurunan tiang hasil pengujian lapangan dari beberapa tiang bor berinstrumentasi dengan diameter $60 \mathrm{~cm}$ sampai $90 \mathrm{~cm}$ pada tanah kohesif seperti pada Gambar.1. Kurva tersebut menunjukkan bahwa transfer beban maksimum atau termobilisasi maksimum terjadi pada perpindahan tiang mendekati $0,6 \%$ dari diameter tiang.

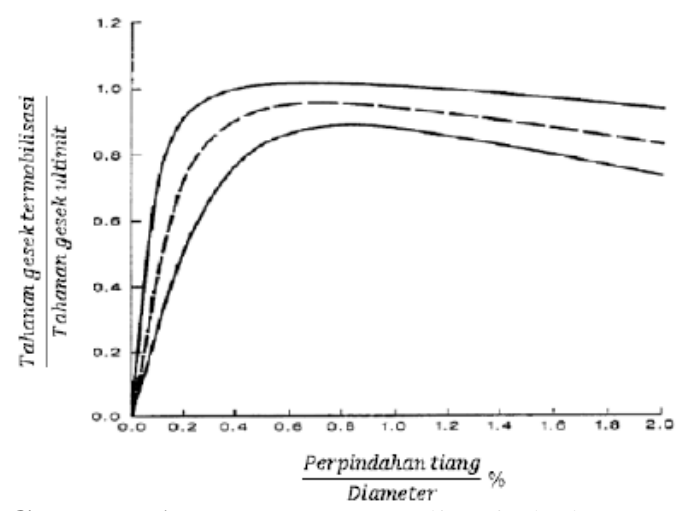

Gambar.1. Kurva normalisasi hubungan tahanan gesek dan penurunan untuk tiang bor pada tanah lempung [1]

Kraft [2] dalam Reese dkk. [1] mengemukakan bahwa transfer beban pada tahanan gesek tiang dipengaruhi oleh diameter tiang, kekakuan tiang aksial, panjang tiang dan distribusi dari kekuatan atau kekakuan tanah di sepanjang tiang.

\section{Tahanan gesek satuan termobilisasi (Rs) pondasi tiang pada tanah lempung}

Metode Omer dkk. (2010)

Omer dkk. [3] memberikan metode empirik untuk analsis tahanan gesek termobilisasi dan penurunan tiang pada tanah lempung berdasarkan metode Vijayvergiya [4]. Nilai $k_{t}$ yang digunakan diperoleh dari korelasi antara modulus gesek tiang saat tahanan gesek satuan termobilisasi sepenuhnya $\left(k_{t}=\frac{f_{s}}{\delta_{c}}\right)$ dan diameter tiang (d) terhadap kuat geser tanah $\left(\tau_{s}\right)$ sekitar tiang seperti pada Gambar 2.

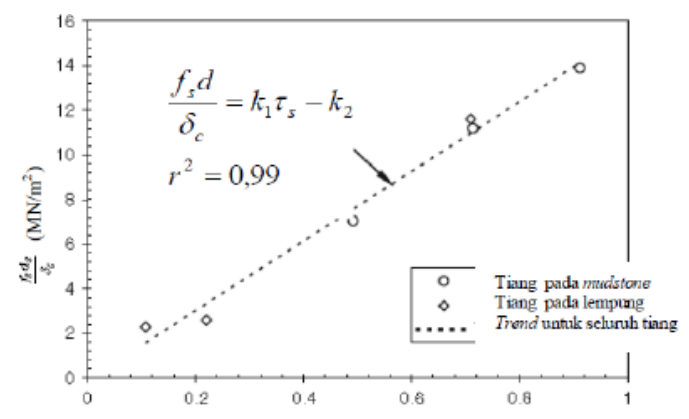

Gambar.2 Korelasi nilai $\frac{f_{s} d}{\delta_{c}}$ terhadap $\tau_{s}$ [3]

Metode Vijayvergiya (1977)

Vijayvergiya [4] dalam Mosher dkk. [5] mengusulkan bahwa tahanan gesek satuan yang termobilisasi adalah fungsi dari perpindahan (displacement) tiang 
yang terjadi seperti yang ditunjukkan pada Gambar.3

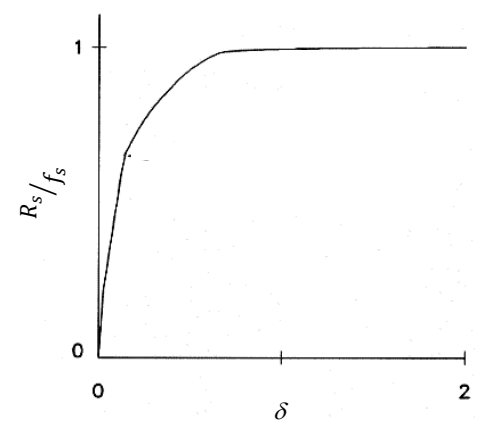

Gambar.3 Grafik hubungan tahanan gesek satuan termobilisasi pada perpindahan tiang. [4] [5].

\section{METODE PENELITIAN}

\section{Prosedur pembuatan box uji model}

Pembuatan box uji meliputi dari tahapan awal persiapan, tahapan pembuatan kerangka dan dinding serta dilanjutkan dengan tahapan finishing yang dilengkapi dengan alat ukur gaya dan pergerakan.

\section{Tahapan persiapan}

Pada tahap persiapan ini mulai menghitung kebutuhan bahan dan alat yang akan dipergunakan. Kebutuhan bahan dan alat yang diperlukan ditabelkan sehingga penyediaan bahan dan alat dapat dilakukan sesuai kebutuhan. Kemudian dilanjutkan dengan pemotongan bahan sesuai dengan ukuran dan jumlah yang dibutuhkan untuk pembuatan model. Dalam pemotongan diupayakan agar penggunaan bahan se-efisien mungkin dengan menghindari kesalahan ukuran maupun jumlah dalam pemotongan. Hal ini dapat dilakukan dengan pembuatan tabel ukuran pemotongan dan jumlah potongan bahan yang diperlukan. Pada kondisi ini dapat dievaluasi tentang jumlah dan jenis bahan yang diperlukan, apabila masih terdapat kekurangan bahan maka masih bisa dipenuhi.

\section{Tahapan perakitan}

Perakitan penyambungan kerangka box uji dengan menggunakan system las listrik. Penyempurnaan kerangka box uji dengan pengukuran kesikuan sudutsudut pertemuan kerangka serta memperbaikinya apabila terdapat kekurangan. Setelah pembuatan kerangka telah selesai maka dapat dilakukan pemasangan dinding- dinding samping dari bahan multiplek, serta alas lantai box uji dari bahan plat baja. Selanjutnya dilakukan pembuatan angkur dari bahan baja berbentuk holo (pipa kotak berlubang). Angkur yang terbuat dari kerangka baja ini berfungsi sebagai penempatan alat-alat ukur apabila dikemudian hari box uji ini dipergunakan. Pada tahap terakhir adalah pekerjaan finishing yang berupa pengecatan kerangka maupun dinding box uji serta pemasangan asesoris lainnya. Dalam pengoperasiannya box uji ini dilengkapi dengan proving ring untuk mengukur gaya dan dial gauge dipakai untuk mengukur pergerakan dengan ketelitian tertentu.

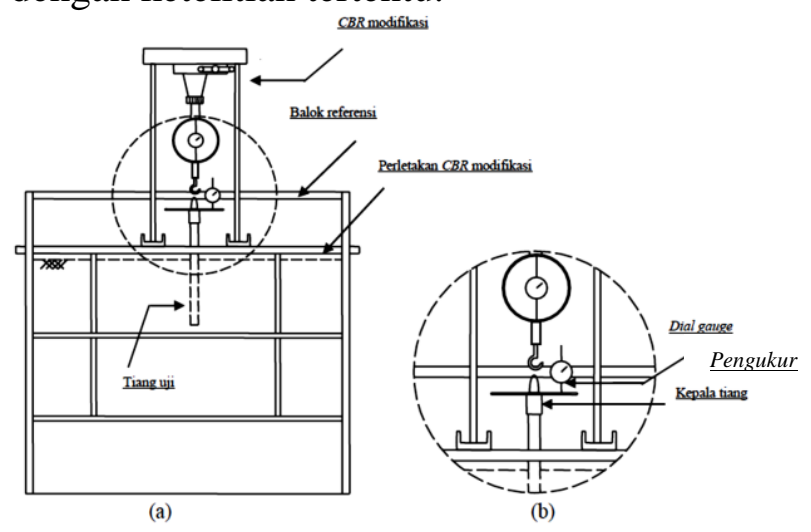

Gambar 4. Gambar Box UJi

\section{HASIL dan PEMBAHASAN}

\section{Hasil Uji Model Tiang}

Hasil uji beban tarik seluruh tiang pada tanah lempung untuk setiap perpindahan 
axial tiang diperlihatkan pada Gambar.5.

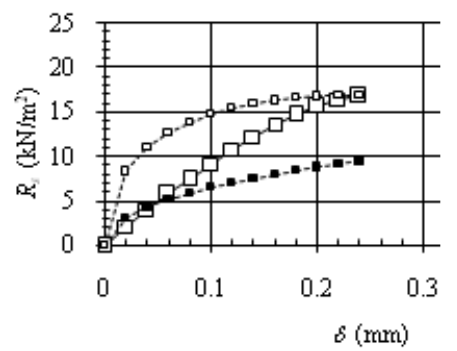

(a)
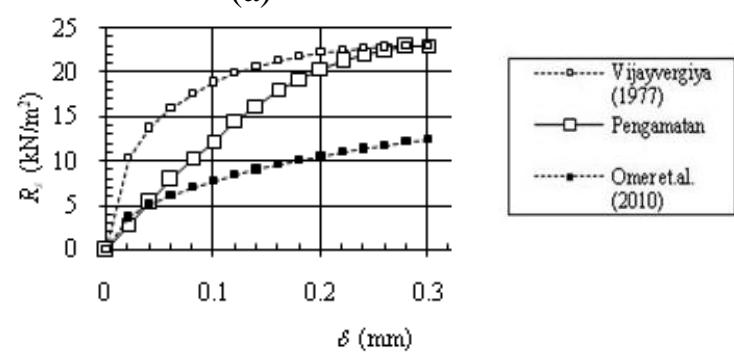

(b)

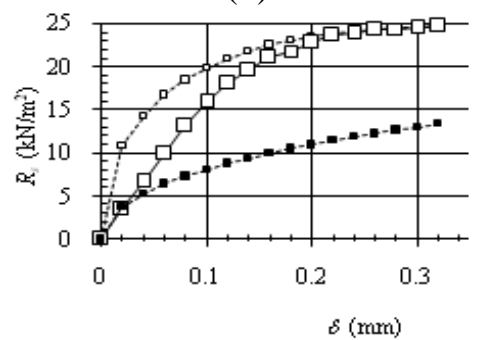

(c)

Gambar.5. (a) Tiang $d=0,02 \mathrm{~m}$

(b) Tiang $\mathrm{d}=0,03 \mathrm{~m}$

(c) Tiang $\mathrm{d}=0,04 \mathrm{~m}$

Rangkuman hasil uji tahanan gesek satuan termobilisasi $\left(R_{S}\right)$ untuk seluruh tiang dalam Gambar.5 dicantumkan dalam Tabel.1.

Tabel.1 Rangkuman Nilai $R_{S}$

\begin{tabular}{cccc}
\hline No & $\mathrm{d}(\mathrm{m})$ & $\delta_{c}(\mathrm{~mm})$ & $R_{S}\left(\mathrm{kN} / \mathrm{m}^{2}\right)$ \\
\hline & & & \\
1 & 0,02 & 0,26 & 10,79 \\
2 & 0,03 & 0,30 & 21,05 \\
3 & 0,04 & 0,32 & 24,65 \\
\hline
\end{tabular}

Hubungan tahanan gesek satuan termobilisasi sepenuhnya $\left(k_{t}=\frac{f_{s}}{\delta_{c}}\right)$ dan diameter tiang $(d)$ terhadap kuat geser tanah $\left(\tau_{s}\right)$ sekitar tiang dari Omer dkk, 2010 [3] dalam Gambar 2 dapat dikembangkan seperti pada persamaan 1.

$R_{s}=f_{s} \sqrt{\frac{\delta\left(k_{1} \tau_{s}-k_{2}\right)}{f_{s} d}}\left(2-\sqrt{\frac{\delta\left(k_{1} \tau_{s}-k_{2}\right)}{f_{s} d}}\right)$

dengan

$d=$ diameter tiang $(\mathrm{m})$

$R_{s}=$ tahanan gesek satuan termobilisasi $\left(\mathrm{kN} / \mathrm{m}^{2}\right)$

$f_{s}=$ tahanan gesek ultimit satuan $\left(\mathrm{kN} / \mathrm{m}^{2}\right)$

$\delta=$ perpindahan (displacement) tiang (m)

$k_{t}=$ modulus gesek tiang yang didapatkan saat tahanan gesek satuan termobilisasi sepenuhnya $\left(\mathrm{kN} / \mathrm{m}^{3}\right)$

$\delta_{c}=$ perpindahan $($ displacement $)$ tiang kritis (m).

\section{KESIMPULAN}

Tahanan gesek satuan termobilisasi dan perpindahan tiang kritis dari diameter tiang uji $0,02 \mathrm{~m}, 0,03 \mathrm{~m}$ sampai $0,04 \mathrm{~m}$ menunjukkan kecenderungan peningkatan rata-rata sekitar $17,1 \%$ dan 7\%. Pada perpindahan tiang kecil, tahanan gesek satuan termobilisasi berdasarkan Metode Omer dkk.(2010) [3] memberikan hasil yang lebih mendekati hasil pengamatan.

Hasil pengujian belum sepenuhnya memastikan nilai tahanan gesek yang terjadi pada tiang dimensi lapangan, sehingga sebaiknya dilakukan uji skala penuh dipengujian lanjutan berikutnya.

\section{DAFTAR PUSTAKA}

[1] Reese dkk (2006)

[2] Kraft (1981)

[3] Omer, J., Delpak, R., \& Robinson, R. (2010). An Empirical Method for Analysis of Load Transfer and Settlement of Single Piles. Springer Science Business Media B.V, 483501.

[4] Vijayvergiya (1977) 
[5] Mosher, R., \& Dawkins, W. (2000).

Theoretical Manual of Piles

Foundation. Washington, DC: US

Army Corps of Engineers. 
Andikanoza Pradipta dan A'isyah Salimah, Pengaruh Diameter Tiang 